\title{
0 cuidado em saúde no ciclo gravídico-puerperal sob a perspectiva de usuárias de serviç̧os públicos ${ }^{*}$
}

Cristina Maria Garcia de Lima Parada ${ }^{1}$ Vera Lúcia Pamplona Tonete ${ }^{2}$

PARADA, C.M.G.L.; TONETE, V.L.P. Healthcare during the pregnancy-puerperium cycle from the perspective of public service users. Interface - Comunic., Saúde, Educ., v.12, n.24, p.35-46, jan./mar. 2008.

The aim of this study was to understand social representations of puerperal women regarding healthcare during the prenatal, delivery and puerperal periods, within the regional context of public health services in the interior of the State of São Paulo. Taking a qualitative research approach, data were collected in 2004 using semi-structured interviews and were organized using the collective subject discourse method. The prenatal and birth humanization program (PHPN) was the theoretical reference point for discussing the results. The puerperal women's perspectives regarding healthcare during the pregnancy-puerperium cycle demonstrated the importance of interpersonal relationships, indispensability of technical quality in the care provided and correctness of the perception that the subject of attention is the woman, and that, as such, she should have effective participation in the process. It was concluded that the PHPN guidelines should be incorporated more broadly into healthcare practices aimed towards women and that specific indicators for assessing the care dimensions demonstrated by this study should be adopted.

Key words: Prenatal care. Delivery. Postpartum period. Health assessment. Qualitative research. Humanized delivery.
O objetivo do trabalho foi apreender as representações sociais de puérperas sobre o cuidado em saúde no período pré-natal, no parto e no puerpério, em um contexto regional de serviços públicos de saúde do interior paulista. Seguindo a abordagem de pesquisa qualitativa, os dados foram colhidos por meio de entrevistas semiestruturadas, realizadas em 2004, e organizados segundo o método do Discurso do Sujeito Coletivo, tendo o Programa de Humanização do Pré-natal e Nascimento (PHPN) como referencial teórico para discussão dos resultados. A perspectiva das puérperas sobre o cuidado em saúde no ciclo gravídico-puerperal evidenciou a importância das relações interpessoais, a essencialidade da qualidade técnica do atendimento e a propriedade da percepção de que o sujeito da atenção é a mulher e, como tal, dela deve participar efetivamente. Conclui-se que as diretrizes do PHPN devem ser incorporadas de forma mais ampla nas práticas de saúde voltadas à mulher, recomendando-se a adoção de indicadores específicos para avaliação das dimensões do cuidado evidenciadas por este estudo.

Palavras-chave: Cuidado pré-natal. Parto. Período pós-parto. Avaliação em saúde. Pesquisa qualitativa. Parto humanizado.

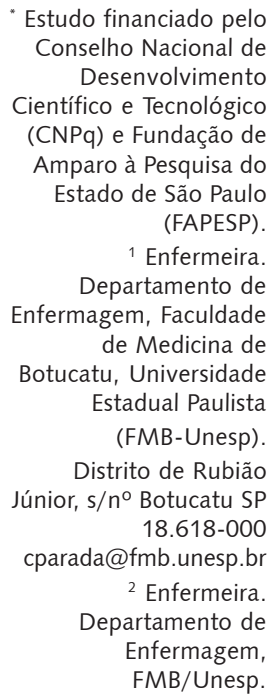

Estudo financiado pelo Conselho Nacional de Desenvolvimento Científico e Tecnológico (CNPq) e Fundação de Amparo à Pesquisa do Estado de São Paulo (FAPESP). 1 Enfermeira. Departamento de Enfermagem, Faculdade de Medicina de Botucatu, Universidade Estadual Paulista (FMB-Unesp). Distrito de Rubião Júnior, s/nº Botucatu SP 18.618-000 cparada@fmb.unesp.br 2 Enfermeira.

Departamento de Enfermagem, FMB/Unesp. 


\section{Introdução}

O paradigma da promoção à saúde engloba, entre seus elementos constituintes: a integralidade do cuidado e a prevenção de agravos, o compromisso com a qualidade de vida e a adoção da participação comunitária como peça fundamental de planejamento e avaliação dos serviços (Ayres, 2004).

Considerando-se essas questões, há de se supor a importância da contribuição que os usuários de serviços de saúde possam dar aos estudos sobre o processo assistencial, especialmente quando se pretende abordar a humanização do cuidado em saúde, como no caso da presente investigação.

O termo humanização vem sendo utilizado há mais de quarenta anos com sentidos diversos, incluindo desde uma perspectiva caritativa até a introdução do discurso dos direitos dos cidadãos ao acesso a uma atenção de qualidade. Em recente estudo desenvolvido com gestores de maternidades do Rio de Janeiro, os principais significados atribuídos ao termo diziam respeito: à qualidade da relação interpessoal entre profissionais e usuários; ao reconhecimento dos direitos dos clientes e à democratização das relações de poder entre eles e os profissionais; à desmedicalização da atenção ao parto e nascimento; à promoção de vínculo entre familiares, mãe e recém-nascido, e à valorização dos profissionais de saúde (Deslandes, 2005). Neste estudo, optou-se por adotar essa multiplicidade de significados.

Especificamente na área obstétrica, no Brasil, discussão mais ampla sobre autonomia e humanização do cuidado tem-se mostrado relativamente recente e reflete o descontentamento com o modelo de atenção excessivamente intervencionista desenvolvido no país, especialmente relacionado à atenção ao parto (Serruya, Lago, Cecatti, 2004a).

Em termos de políticas públicas de saúde, essa questão é claramente tratada, pela primeira vez, no Programa de Humanização do Pré-natal e Nascimento (PHPN), criado pelo Ministério da Saúde no ano 2000. Tal programa apresenta, como um de seus fundamentos, o direito à humanização da assistência obstétrica e neonatal como condição primeira para o acompanhamento adequado a mulheres e recém-nascidos (Brasil, 2000).

Tendo em vista a promoção da saúde materno-infantil, a importância da humanização da assistência no ciclo gravídico-puerperal, e por se considerar a perspectiva das mulheres sobre o cuidado recebido neste período, é que se propôs a presente pesquisa. Estabeleceu-se, como objetivo, apreender as representações sociais de puérperas sobre o cuidado em saúde no período pré-natal, no parto e no puerpério, em um contexto regional de serviços públicos de saúde do interior paulista.

Com a produção desse conhecimento, espera-se subsidiar gestores responsáveis pela atenção à saúde da mulher, na formulação e implementação de políticas públicas nesta área, bem como contribuir para que os demais sujeitos envolvidos, trabalhadores e usuários, ao compartilharem esse conhecimento, possam participar ativamente desse processo.

\section{Material e método}

O estudo foi realizado em 2004, na região da antiga Direção Regional de Saúde XI - Botucatu, composta por 31 municípios, sendo que vinte deles aderiram ao PHPN até 2003 e, por isso, foram incluídos na investigação. Tais municípios têm tamanhos variados (menos de cinco mil a mais de 110 mil habitantes) e, na região, a área de serviços é a que mais emprega no mercado formal (Fundação Seade, 2006).

Com relação ao atendimento na área de obstetrícia, os vinte municípios estudados possuem unidades de atenção básica para atendimento pré-natal e 11 possuem maternidade para atendimento ao parto de baixo risco, porém, com número variável de leitos: três nos hospitais com menor média mensal de partos e 29 naquele com maior média. Na região, existe apenas um serviço para atendimento terciário em obstetrícia.

A abordagem de pesquisa utilizada foi a qualitativa, definida como aquela que se preocupa com um nível de realidade que não pode ser quantificado, trabalhando com o universo de significados, motivos, aspirações, crenças, valores e atitudes que, por sua vez, correspondem a um espaço mais 
profundo das relações, dos processos e fenômenos que não podem ser reduzidos à operacionalização de variáveis (Minayo, 1994). O referencial teórico utilizado para discussão dos resultados foi o PHPN (Brasil, 2000).

Para escolha dos sujeitos desta investigação, dois critérios básicos foram utilizados: que os mesmos exprimissem as diversidades de procedência e experiência. Considerando a procedência, foram incluídas mulheres residentes em municípios de diferentes tamanhos, com maternidades de diferentes portes e graus de complexidade e com diferentes formas de organização da atenção básica; com relação à experiência, foram consideradas variações de história obstétrica, tipo de parto e vivência ou não de situações como: participação em grupo de gestante, intercorrências no ciclo gravídico-puerperal e presença de familiar acompanhante no momento do parto.

Foram realizadas 34 entrevistas semi-estruturadas a puérperas, baseadas em questões norteadoras, em visitas domiciliares após o parto, em dois encontros com cada sujeito. No primeiro, solicitava-se a participação de algum familiar que pudesse contribuir, de fato, para que a puérpera respondesse à entrevista e, no segundo, complementava-se a entrevista apenas com a puérpera. Esta estratégia permitiu retomar, no segundo encontro, questões que mereciam aprofundamento ou esclarecimento. Destaca-se que a realização das entrevistas fora do serviço de saúde destinou-se a dar mais liberdade às mulheres quando da abordagem do cuidado recebido.

As questões norteadoras citadas relacionam-se às representações elaboradas pelas puérperas sobre o cuidado em saúde obtido nos serviços de assistência pré-natal e o atendimento recebido para o parto, a saber: como foi o seu atendimento pré-nata? Do que você gostou e do que não gostou durante o seu atendimento pré-natal? Como você foi cuidada durante sua internação para o parto? Do que você gostou e do que não gostou durante o parto? Como foi o seu atendimento e o do seu bebê após o parto?

A organização dos dados colhidos foi realizada conforme proposta de Lefèvre e Lefèvre (2003), e consistiu na determinação da idéia central - afirmação(ões) que permite $(\mathrm{m})$ traduzir o essencial do conteúdo discursivo explicitado pelos sujeitos em seus depoimentos; identificação das expressõeschave - transcrições literais de parte dos depoimentos, que permitem o resgate do que é essencial no conteúdo discursivo e construção do discurso do sujeito coletivo (DSC) - reconstrução, com pedaços de discursos individuais, de tantos discursos-síntese quantos forem necessários, para expressar um dado pensar ou representação social sobre um fenômeno. Destaca-se que a aplicação da técnica do DSC a um grande número de pesquisas empíricas tem demonstrado sua eficácia para o processamento e a expressão de opiniões coletivas (Lefèvre \& Lefèvre, 2006).

O projeto desta investigação foi analisado e aprovado pelo Comitê de Ética em Pesquisa da Faculdade de Medicina de Botucatu da Universidade Estadual Paulista e atendeu a todas as normas previstas para pesquisas realizadas com seres humanos.

\section{Resultados e discussão}

As entrevistas foram numeradas de 1 a 34 e, quando determinadas expressões-chave contribuíram com a elaboração de algum DSC, na sua seqüência, o número da entrevista da qual cada expressão foi transcrita está assinalado. Ao término de cada DSC, também apresenta-se a idéia central relacionada a ele. Os resultados estão apresentados ordenadamente, segundo as representações sociais apreendidas sobre o cuidado em saúde na atenção pré-natal, ao parto e ao puerpério.

\section{Atenção pré-natal}

A análise das representações elaboradas pelas puérperas quanto ao cuidado em saúde na atenção pré-natal está apresentada a seguir, com base em dois temas: relações interpessoais: fragilidades e fortalezas e qualidade técnica como fator de humanização. 
Tema 1- Relações interpessoais: fragilidades e fortalezas

As representações positivas sobre o cuidado em saúde durante o período pré-natal emergiram dos discursos das puérperas, relacionando-o à interação profissionais-usuários, caracterizada pela escuta, atenção e cordialidade, conforme pode ser observado no Discurso 1:

DSC 1 - Eu gostei de tudo do atendimento, foi ótimo, não tenho do que reclamar, sempre me trataram super bem. Eu conversava com todo mundo, tinha amizade com todas as enfermeiras, a médica era muito atenciosa, educada, simpática... gostei do jeito que ela falava com a gente. Até as coisas de casa eu perguntava pra ela. (IC 1- Amizade-proximidadevínculo. Entrevistas n. 1-8, 10,11, 13-23, 25-30, 32-34)

O cuidado satisfatório é, portanto, representado como aquele desenvolvido com simpatia e educação. Como a literatura correlata evidencia, constatou-se a importância das relações interpessoais e do acolhimento nos serviços de saúde, entendido como um cuidado aberto à escuta (Deslandes, 2005). Essas relações devem viabilizar uma rede de conversações que é essencial ao cuidado, na medida em que contribui com o estabelecimento de negociações entre as necessidades dos usuários e os meios de satisfazê-las (Teixeira, 2001).

Em contraponto, algumas mulheres, ao abordarem o cuidado pré-natal, representaram-no de maneira negativa, apontando, sobretudo, a falta de diálogo com o médico:

DSC 2 - Não gostei do meu pré-natal, o médico era muito bruto, não conversava e eu me sentia um pouco insegura. Nossa, ele me fez chorar de nervosa, não conversava, não falava: quando for o dia do seu parto, vai acontecer assim, você tem que ter calma. Ele só me chamava de boizão, porque eu engordei muito. (IC 2 - Não me dei bem com o médico e não gostei do meu pré-natal. Entrevistas n. 9, 12, 24, 31)

Em um contexto em que a atenção ao ciclo gravídico-puerperal está centrada no processo de trabalho médico, como ocorre nos municípios da região estudada, a interação efetiva e humanizada das gestantes com esses profissionais assume extrema importância para o sucesso da atenção e os depoimentos acima denunciam o grande distanciamento dessa meta.

De fato, o preparo da mulher para o parto deve ser iniciado precocemente, ainda no pré-natal. Isso requer um esforço viável, no sentido de sensibilizar e motivar os profissionais de saúde da rede básica para trabalharem com as gestantes, preparando-as psíquica e fisicamente (Brasil, 2003). Segundo o Discurso 2, porém, as mulheres manifestaram terem sentido falta deste preparo; e, ainda sobre esse discurso, o mínimo que se espera de um serviço de saúde é que trate a gestante com respeito. Para o Ministério da Saúde, a humanização requer, entre outras coisas, que se chame a mulher pelo nome, evitando-se, inclusive, termos como "mãezinha" ou "dona" (Brasil, 2003). Desta forma, parece inconcebível que um profissional, qualquer que seja sua formação, possa chamar uma gestante de "boizão".

Pelo exposto, pode-se inferir que as representações sobre o cuidado em saúde na Atenção Prénatal, em parte, ancoram-se na perspectiva de um atendimento humanizado, que se dá mediante uma boa relação entre os profissionais e os clientes, proporcionando segurança às mulheres e considerando-as sujeitos do cuidado.

\section{Tema 2 - Qualidade técnica como fator de humanização}

Sob outra perspectiva, representações positivas sobre o cuidado em saúde no período pré-natal, também foram apreendidas, com base em vários depoimentos, especialmente, como decorrentes da qualidade técnica dispensada, relacionada à disponibilidade de exames, presteza no atendimento e desenvolvimento de ações básicas, conforme exemplifica o discurso a seguir:

DSC 3 - Eu fiz o pré-natal certinho, não perdi nenhuma consulta, fiz todos os exames. No dia da gestante, ele (o médico) chega ali, atende no horário e, com muita atenção, indica como 
fazer as coisas pra gente se sentir bem na gravidez, examina tudinho... e todas as vezes que eu precisei, fui atendida, com tudo do melhor. (IC 3 - Fui atendida com tudo do melhor. Entrevistas n. 1, 5, 7, 8, 11, 12, 14-23, 25-30, 32,34)

Já os Discursos 4 a 6 deixam transparecer as representações negativas sobre o cuidado em saúde na Atenção Pré-natal, quando não há o atendimento com a devida qualidade técnica:

DSC 4 - Eu não gostei muito, o doutor não marcava as coisas na minha carteirinha, o tamanho da minha barriga, tinha um monte de coisa sem marcar. (IC 4 - $O$ doutor não marcava as coisas na minha carteirinha. Entrevistas n. 9, 24, 31, 33)

DSC 5 - Eu senti falta de um ultra-som, eu achei que deveria ter sido feito e não foi. O aparelho do Estado estava quebrado e o do município tinha pra depois que eu ganhasse. (IC 5 - Tenho reclamação sobre o ultra-som. Entrevistas n. 1, 11, 18, 21, 25, 26)

DSC 6 - Não gostei dos exames, os primeiros que eu fiz eles perderam, depois eu repeti e falaram que estava alterado, me encaminharam pra Botucatu, mas em Rubião (serviço terciário), fiz exame de novo e eu não estava com a doença. (IC 6 - Não gostei dos exames. Entrevistas n. $2,4,10,11)$

A concepção que orientou a criação do PHPN pressupõe que a humanização da assistência prénatal requer o cumprimento de um conjunto de procedimentos básicos, a fim de prevenir agravos na gestação e garantir o direito fundamental de toda mulher à experiência da maternidade de maneira segura (Serruya, Lago, Cecatti, 2004a); entre tais procedimentos, inclui-se a realização de exames laboratoriais no início e final da gravidez. Porém, nesse programa não são abordadas explicitamente questões como: procedimentos clínicos mínimos, instrumentos de registro, nem exames complementares como o ultra-som - itens que emergiram dos discursos das puérperas, indicando que, de alguma forma, são valorizados por elas e, por vezes, não estão acessíveis.

\section{Atenção ao parto}

A seguir, apresenta-se a análise das representações elaboradas pelas puérperas quanto ao cuidado em saúde no momento do parto, subdividida em quatro temas: o acolhimento à parturiente, apoiando as mulheres durante o parto, a mulher como protagonista no processo de atenção ao parto e a qualidade técnica do cuidado.

\section{Tema 1 - $\mathrm{O}$ acolhimento à parturiente}

Com o Discurso 7, pode-se perceber a importância da sintonia entre os profissionais e as parturientes que representaram positivamente o cuidado em saúde durante o parto com base no acolhimento experienciado:

DSC 7- Todo mundo falava mal, diziam que os médicos eram estúpidos, deixavam você sozinha, mas eu não tenho do que reclamar, me trataram super bem. Logo que cheguei, fui atendida, a médica foi boazinha, educada, teve paciência, falava pra eu não ficar nervosa, senão fazia mal pro neném... dou nota 10 , desde as faxineiras até as enfermeiras. (IC $7-M e$ trataram super bem. Entrevistas n. 1, 6, 8, 12, 18, 20, 27, 29)

Nesse discurso, destaca-se o acolhimento com que as parturientes foram recebidas, traduzido por termos como: educação, bondade, paciência e presteza. Observa-se que tais representações se ancoram na idéia de que um atendimento tranqüilo viabiliza um parto também tranqüilo. Pelo Discurso 8, pode-se constatar, em contrapartida, que a falta de acolhimento pode gerar sérias distorções: 
DSC 8 - Meus filhos não nascem normal, já tive duas cesáreas. A minha menina caçula morreu na minha barriga e não nascia. Então, quando eu comecei a sentir mal, falei com o doutor e ele me disse: vem quarta-feira, se der, eu faço sua cesárea. Eu pensei: mas vou esperar o neném morrer? Aí, eu fui em outro médico e ele falou que já era pra eu ter ganhado. Então eu paguei 800 pro médico e 400 pro hospital e ele fez a cesárea rapidinho. (IC 8 - Eu paguei e a cesárea foi feita rapidinho. Entrevistas n. 11, 17)

Considerando que os sujeitos dessa investigação são mulheres atendidas pelo Sistema Único de Saúde (SUS), o Discurso 8 revela um problema ético importante. A situação descrita explicita uma representação do direito ao cuidado em saúde, mesmo no serviço público, como relacionado a pagamento, ancorando-se na idéia de que apenas quando você paga pelo atendimento ele é realizado a contento, o que também é mencionado no Discurso 9:

DSC 9 - Eu não gosto quando a gente chega ao hospital e não é bem atendido, como quem tem (dinheiro). Você está esperando ali, chega um rico que está pagando, eles vão atendendo aquele primeiro e a gente fica esperando. (IC 9 - Quem tem dinheiro, tem precedência. Entrevistas n. 5, 7)

Os Discursos 10 e 11 indicam que algumas parturientes deste estudo perambularam por vários serviços até serem atendidas, fato este de extrema gravidade, já que é no período próximo ao parto que ocorre a maioria das mortes maternas (Brasil, 2003). Esses discursos deixam transparecer que o cuidado em saúde efetivo é representado pela garantia de atendimento.

DSC 10 - No oitavo mês o médico falou que ia ser cesárea mesmo, e eu tinha certeza, os outros eu tinha ficado esperando até a última hora e não nasceram normal. Cheguei lá e a enfermeira falou que estava encaixado, pronto pra cortar, mas o médico mandou eu esperar, pra fazer cesárea no outro dia. Mas no outro dia ele não fez, mandou eu vir embora de novo. Aí eu fui procurar o doutor " $X$ " (médico do pré-natal), conversei com ele e ele falou pra eu catar o plantão de outro. (IC 10- Na hora me mandaram embora e eu tive que procurar outro atendimento. Entrevistas n. 7, 13, 14)

DSC 11 - O médico foi muito estúpido, um grosso. Estava saindo líquido e ele falou que não estava na hora, que era pra eu ir embora e voltar sexta-feira. Tornei a passar com ele e ele foi mais mal educado ainda. Falou: qualquer dorzinha normal você vem correndo? (IC 11- O médico falou que com qualquer dorzinha eu procurava atendimento. Entrevistas n. 16, 31).

A fim de minimizar o problema da busca de atendimento no momento de dar à luz, o PHPN preconiza a vinculação dos serviços de Atenção Pré-natal e ao Parto (Brasil, 2000a), o que parece não estar surtindo efeito nas maternidades estudadas. Muitas vezes, a dificuldade surge pela ausência de acolhimento e vínculo entre o profissional e a gestante sendo, apenas a vinculação formal dos serviços, insuficiente.

\section{Tema 2 - Apoiando as mulheres durante o parto}

O respeito à mulher durante o atendimento é pressuposto fundamental para a humanização do parto. Nesse sentido, informá-las sobre os diferentes procedimentos a que serão submetidas, esclarecer suas dúvidas e aliviar sua ansiedade são atitudes relativamente simples que requerem, entre outras coisas, boa vontade do profissional (Brasil, 2003). Essas questões estão presentes no Discurso 12, no qual as mulheres identificam, basicamente, o cuidado em saúde como as explicações que receberam durante o parto:

DSC 12 - Depois eu internei e fiquei com a enfermeira, que começou a me explicar que não era um bicho-de-sete-cabeças, que não adiantava ficar nervosa, não ia ajudar em nada. Aí 
foi tranqüilo, um pouco dolorido, mas eu achei legal. (IC 12 - Com as explicações tive um parto tranqüilo. Entrevistas n. 1, 4, 6, 12, 18, 20, 34)

Com o Discurso 13, observa-se também que o cuidado em saúde efetivo é representado pelo apoio recebido no momento do parto:

DSC 13 - A enfermeira segurou minha mão, descontraiu, me ajudou muito ali, com a pouca experiência que ela tinha. Ficou o tempo todo lá junto e foi muito bom, deu pra acalmar bastante. É gente que cuida da gente com carinho. (IC 13 - Tive apoio o tempo todo. Entrevistas n. 1, 9, 10, 12, 18, 21-23, 28, 32, 34)

Apreende-se, do Discurso 13, o importante papel do profissional apoiando a parturiente, e um sentimento positivo dela em relação ao trabalho de parto. A vivência que a mulher tem da parturição pode ser prazerosa, positiva ou traumática, dependendo de condições intrínsecas a ela e à gestação - como sua maturidade e experiências pessoais ou familiares anteriores - e até àquelas diretamente relacionadas ao sistema de saúde, como a assistência recebida no pré-natal e durante o parto (Brasil, 2003).

Estudos sobre o apoio por uma única pessoa durante o parto, seja ela uma doula, parteira ou enfermeira, mostraram que o apoio físico e empático contínuo durante o trabalho de parto resulta em benefícios, como a diminuição na sua duração, no uso de medicações e analgesia, de partos operatórios e depressão neonatal (OMS, 1996).

Segundo o PHPN, as unidades de saúde devem receber com dignidade a mulher, seus familiares e o recém-nascido, o que requer atitude ética e solidária por parte dos profissionais, organização da instituição de modo a criar um ambiente acolhedor e adotar condutas hospitalares que rompam com o tradicional isolamento imposto à mulher (Serruya et al., 2004b). A presença de um acompanhante, indicado pela parturiente, durante o trabalho de parto também tem sido preconizada como medida em favor da humanização da atenção, sendo atualmente um direito legalmente constituído (Brasil, 2003).

Estudo desenvolvido em uma maternidade que institucionalizou várias rotinas constantes do ideário da humanização, evidenciou resistência apenas inicial dos profissionais à presença do acompanhante, sendo essa posteriormente estimulada pela equipe, por representar uma fonte de apoio, facilitando o trabalho de parto (Tornquist, 2003). Representação favorável do cuidado em saúde emergiu dos depoimentos quando o referido direito foi respeitado:

DSC 14 - Minha tia ficou o tempo todo do meu lado, o médico deixou... eu não queria ficar sozinha e foi muito bom. (IC 14- Não fiquei sozinha e foi muito bom. Entrevistas n. 1, 9, 12, $20,28)$

Os métodos de preparação para o parto objetivam, em geral, evitar a tríade medo-tensão-dor, pois se considera que o conhecimento destrói o temor e evita a tensão, controlando a dor (Brasil, 2003). A ausência de apoio, atendimento ou orientação pode resultar em medo - de morrer ou de perder o bebê - e, em muito sofrimento, conforme se percebe no Discurso 15:

DSC 15 - Comecei a sentir dores de madrugada. Quando amanheceu, fui pro hospital, a médica falou que não estava na hora e me mandou pra casa. Aí eu falei: mas já passou dos nove meses, mas ela não falou nada, então eu fiquei com medo. No dia seguinte, meu marido pediu a ambulância e me levou, porque eu estava travada e com dor. O doutor que me atendeu falou que não ia me operar... aí eu estava sangrando e bastante nervosa, com medo de perder a criança. A pressão subiu e eu achei que ia morrer. (IC 15 - A médica não explicou, fiquei com medo... Entrevistas n. 13, 24)

No discurso, a representação que se apreende é de um cuidado insatisfatório, já que a falta de orientação sobre o que estava ocorrendo fez com que a mulher passasse a ver o parto como um 
momento de perigo, tanto para ela quanto para o bebê. A busca por solução dos problemas apresentados foi em vão, ou seja, não se respeitaram aspectos relacionados à humanização. $O$ mesmo pode ser conferido no Discurso 16, onde também se observa referência à dor, que embora inerente ao processo fisiológico do parto, poderia ser minimizada pela presença do acompanhante, de suporte emocional, da utilização de técnicas de alívio e do apoio da equipe.

DSC 16 - Fiquei dois dias internada, sentindo dores e o nenê não nascia... A enfermeira era uma carrasca, me chamava de madame. Os enfermeiros e os médicos daqui não dão atenção, não acreditam que a gente tem dor. Sinceramente, eu pensei que eu ia morrer e ninguém vinha me explicar nada. (IC 16- A hora que eu precisei, não me deram atenção. Entrevistas n. 2, 3, 5, 13, 17, 24, 26, 30)

Em algumas situações, ficam claras as diferenças de conduta entre os membros da equipe, como mostra o Discurso 17:

DSC 17 - Eu ia e voltava, sentia dor e não dilatava e eles segurando pra não fazer cesárea... A doutora que me atendeu não era muito boa, era estúpida, fez eu me sentir um porco, um porco limpo, desse jeito eu me senti. Mas sempre tem alguém com mais carinho. Aí a enfermeira segurou minha mão e ficou ali, esperando eu me acalmar. (IC 17 - Sempre tem alguém com mais carinho. Entrevistas n. 11, 14, 16, 24, 30)

Nesse discurso, emerge a representação positiva sobre o cuidado no parto, como algo relacionado ao carinho, paciência e solidariedade. Destaca-se que humanizar é envolver-se com as pessoas para melhor entender seus medos, alegrias, ansiedades e expectativas, e, de algum modo, poder ajudar, solidarizar-se (Rattner \& Trench, 2005).

\section{Tema 3 - A mulher como protagonista do trabalho de parto}

O preparo da gestante para o parto abrange a incorporação de um conjunto de cuidados, medidas e atividades que têm como objetivo oferecer à mulher a possibilidade de vivenciar essa experiência como protagonista do processo (Brasil, 2003). As mulheres devem ser vistas como sujeitos que vêm de culturas diferentes e têm emoções e desejos que não são universais (Tornquist, 2003).

Pelo Discurso 18, pode-se verificar que a mulher, por vezes, é ouvida:

DSC 18 - O doutor queria me mandar embora, falou que não estava na hora. Eu falava que não ia, que estava com muita dor. Aí uma doutora me perguntou: você acha melhor ficar ou ir? Eu disse: quero ficar. Aí eu fiquei e ela nasceu. Se tivesse ido embora tinha nascido em casa. (IC 18 - Eles me ouviram, fiquei internada e nasceu. Entrevistas n. 25, 26, 31)

Em muitos serviços, porém, a mulher continua sendo tratada como mera coadjuvante, conforme se observa nos Discursos 19 e 20:

DSC 19 - [...] a moça falou que não tinha estourado a bolsa e já tinha, aí o médico falou que estava seis dedos dilatado e me mandou pro pré-parto. Eu não estava agüentando de dor, fiquei uns dois minutos no quarto e na hora que foi pra neném nascer, chamei a enfermeira e ela não me ajudou, foi até bruta. Aí chamaram o médico, ele viu que estava nascendo e mandou respirar e deitar correndo, quase caiu no chão. (IC 19 - Chamei a enfermeira e ela não me ajudou. Entrevistas n. 2, 3, 5, 15, 19)

DSC 20 - No ultra-som eles julgaram que eu estava com três semanas a mais da minha conta e no dia 15 o médico mandou internar. Fiquei com medo, porque eu achava que não estava na hora. Mas aí ele fez a cesárea, só que o pulmão estava prematuro. Eu tinha falado que 
estava de menos. Quase perdi ela, eles tiraram antes do tempo e ela quase morreu. (IC 20 Eu falei que não estava na hora. Entrevistas n. 11, 13)

Os profissionais de saúde desempenham importante papel na atenção ao parto, pois têm a oportunidade de colocar seu conhecimento a serviço do bem-estar da mulher e do bebê, reconhecendo e intervindo nos momentos críticos. Entretanto, devem entender que a mulher, como sujeito do processo, tem o direito de participar das decisões sobre o nascimento, desde que não coloque em risco a evolução do trabalho de parto, sua segurança e a do recém-nascido (Brasil, 2003).

Ressalta-se, porém, que as próprias mulheres têm dificuldades em assumir um papel participativo no trabalho de parto. Dessa forma, para humanizar o atendimento ao nascimento é necessário conscientizá-las, discutindo quais as suas necessidades ou demandas, pois somente assim poderão reivindicar um cuidado melhor (Rattner \& Trench, 2005).

\section{Tema 4 - Qualidade técnica do cuidado}

Conforme discutido anteriormente, a humanização da atenção à saúde das pessoas, além de abranger uma série de diferentes aspectos referentes às idéias, aos valores e às práticas envolvendo as relações entre profissionais de saúde, pacientes e familiares e/ou acompanhantes, também engloba os procedimentos técnicos adotados, as rotinas dos serviços e o relacionamento dos membros da equipe entre si (Rattner \& Trench, 2005).

Do Discurso 21, apresentado a seguir, emergem representações negativas do cuidado, relacionadas à forma como o parto foi conduzido do ponto de vista técnico:

DSC 21 - Na sala de exame, eu perdendo água, demorou pro médico me atender. Eu precisei gritar, porque eles deixaram pra última hora. Me disseram que ele era pequenininho e ia nascer, mas ele vinha e voltava. Aí fizeram aquela força na minha barriga, eu caí da mesa, o anestesista me grudou pela camisola e minha irmã gritou: vocês vão matar minha irmã! Ele (o bebê) quebrou a clavícula e nasceu com a boquinha torta. (IC 21- Por causa do parto meu bebê teve problemas. Entrevistas n. 2, 4, 13, 19, 24-26, 30, 31, 33)

O ponto mais importante e mais complexo da avaliação da qualidade de serviços de saúde reside na avaliação do processo de assistência, que compreende a competência tanto do desempenho técnico quanto a competência da qualidade das relações interpessoais (Rattner \& Trench, 2005). Embora ambas sejam igualmente importantes e devam ser igualmente valorizadas, as representações elaboradas pelas puérperas sobre o cuidado em saúde durante o parto estiveram permeadas pelo desequilíbrio na consideração desses aspectos, expondo as parturientes e seus conceptos a situações desumanas.

É condição fundamental para a humanização do cuidado que os serviços de saúde adotem medidas e procedimentos sabidamente benéficos para o acompanhamento do parto e do nascimento, evitando práticas intervencionistas desnecessárias que, embora tradicionalmente realizadas, não beneficiam a mulher nem o recém-nascido e que, com freqüência, acarretam maiores riscos para ambos (Serruya, Lago, Cecatti, 2004b).

\section{Atenção ao puerpério}

A análise das representações sobre o cuidado em saúde após o parto foi compilada em um único tema: apoio à elaboração da relação mãe-bebê.

\section{Tema 1 - Apoio à elaboração da relação mãe-bebê}

As representações positivas do cuidado em saúde no puerpério relacionaram-se ao auxílio nas primeiras atividades desenvolvidas com o bebê, como exemplificado no DSC 22:

DSC 22 - No primeiro dia as enfermeiras vinham perguntar pra mim se eu precisava de ajuda 
pra dar banho nela, pra cuidar. Toda hora estava passando enfermeira e médico no quarto, perguntando se a gente queria alguma coisa. (IC 22 - Toda hora vinha alguém me ajudar. Entrevistas n. 1, 5, 8-10, 12, 15, 17, 19-23, 25, 27, 28, 32-34)

Após o parto, a mulher tem necessidade de atenção física e psíquica e a relação com seu filho ainda não está bem elaborada. Por isso, as atenções não devem ser concentradas apenas na criança; nesse momento, o alvo da atenção tem de ser a puérpera (Brasil, 2003). Além disso, deve-se lembrar que, após o parto, são comuns a exaustão e o relaxamento, sobretudo se houve um longo período sem adequada hidratação e/ou alimentação, somado aos esforços do período expulsivo. Assim, pode haver sonolência, que exige repouso (Brasil, 2003). Porém, nem sempre se respeita essa necessidade de descanso, como se pode perceber nos dois discursos a seguir:

DSC 23 - Me deixaram lá com o nenê, eu estava anestesiada, longe da campainha e estava duro virar pra dar de mamá, porque eu não podia levantar a cabeça e não tinha como chamar... eu estava desesperada, querendo até ir embora. (IC 23 - Eu não tinha condições de cuidar, mas fui obrigada. Entrevistas n. 2-4, 13, 16, 18, 24, 26, 30, 31)

DSC 24 - Tem umas enfermeiras que são uns cavalos. Eu nem podia andar, por causa da cesariana e da laqueadura, aí ela chegou e falou: vamos tomar banho. Eu levantei e na hora que eu cheguei no banheiro ela me empurrou. Eu sou meio medrosa, mas teve uma hora que até meu marido ficou com medo, falou com a mãe dele e ela ligou lá à noite. (IC 24 - Eu fiquei com medo da enfermeira. Entrevistas n. 7,13,14)

A ausência de atividades educativas, conforme ilustrado no Discurso 25 , leva à discussão de sua importância no puerpério, já que alguns dos sujeitos valorizam esse aspecto como cuidado em saúde a ser recebido neste período:

DSC 25 - Não recebi orientação nenhuma. Fiquei cuidando dele sozinha, fiz dormir, tudo eu. Até que ele chorou a noite inteira e daí ligaram pra minha mãe levar uma chuca e o leite "NAM". Ela levou, o nenê mamou e ficou quieto a noite inteira. (IC 25 - Eu não recebi orientação nenhuma. Entrevistas n. 2-4,13, 16, 18, 24, 26, 30, 31)

O puerpério imediato deve ser valorizado pelo início do processo de vínculo mãe-bebê, devendo ser considerado como o momento de "acabamento" da experiência do parto e como o tempo de ressonância, que pede a abertura de espaço para a escuta, quando pais, avós, familiares e, especialmente, a mãe, estão dilatados, abertos (Rattner \& Trench, 2005) e, assim, prontos para trocarem experiências. Pelas representações aqui apreendidas, pode-se inferir que a vulnerabilidade das puérperas e dos recém-nascidos aos agravos pareceu estar mais evidenciada com a não obtenção do apoio requerido.

\section{Considerações finais}

A perspectiva das usuárias dos serviços públicos sobre o cuidado em saúde no ciclo gravídicopuerperal, privilegiada neste estudo, permite considerar que o momento do parto pode ser caracterizado como de considerável medicalização, muito preso às rotinas e resistente à humanização. Também, em relação a essa perspectiva, pode-se considerar que, nos períodos pré-natal e puerperal, o cuidado não é isento de problemas, sendo as mulheres geralmente tratadas como coadjuvantes, em um processo assistencial por vezes marcado pela ausência de vínculo com os profissionais.

Com base nessas considerações e em coerência com os princípios do PHPN, postula-se que a mulher deva ser reconhecida como principal partícipe do processo anteriormente referido, tendo suas escolhas respeitadas no estabelecimento de práticas que, baseadas em evidências, permitam a sua 
segurança e bem-estar, assim como do recém-nascido. Porém, cabe ressaltar que o PHPN, ao adotar indicadores para avaliação da qualidade da atenção que privilegiam o número de consultas prénatais, a imunização e os exames básicos realizados, não está avançando na inclusão de aspectos que valorizem, de fato, outras dimensões do cuidado, como as relacionadas às questões de gênero.

Por fim, considera-se que o olhar da humanização sobre as representações sociais apreendidas evidencia a importância de se transformarem as práticas regionais voltadas à atenção ao ciclo gravídico-puerperal, sobretudo no que diz respeito às relações interpessoais, incluindo o acolhimento e apoio efetivos e extensivos a todas as mulheres, não apenas durante o pré-natal, o trabalho de parto e o parto, mas também para o estabelecimento do vínculo mãe-bebê após o nascimento. Ao mesmo tempo, o referido olhar confirma a essencialidade da qualidade técnica do atendimento e a propriedade da percepção de que é a mulher o sujeito da atenção e, como tal, dela deve participar efetivamente.

\section{Referências}

AYRES, J.R. Norma e formação: horizontes filosóficos para as práticas de avaliação no contexto da promoção da saúde. Ciênc. Saúde Coletiva, v.9, n.3, p.583-92, 2004.

BRASIL. Ministério da Saúde. Parto, aborto e puerpério: assistência humanizada à mulher. Brasil: Ministério da Saúde, 2003.

Portaria no 569 de 01 de junho de 2000. Instituição do Programa de Humanização do Pré-natal e Nascimento no âmbito do Sistema Único de Saúde. Diário Oficial da República Federativa do Brasil. Brasília, 8 jun. 2000.

DESLANDES, S.F. A ótica de gestores sobre a humanização da assistência nas maternidades municipais do Rio de Janeiro. Ciênc. Saúde Coletiva, v.10, n.3, p.615-26, 2005.

FUNDAÇÃO SEADE. Sistema de informações dos municípios paulistas. Disponível em: <http://www.seade.gov.br/produtos/imp/index.php> Acesso em: 7 mar. 2006.

LEFÈVRE, F.; LEFÈVRE, A.M.C. O sujeito coletivo que fala. Interface - Comunic., Saúde, Educ., v.10, n.20, p.517-24, 2006.

O discurso do sujeito coletivo: uma nova abordagem metodológica em pesquisa qualitativa. Caxias do Sul: Educs, 2003.

MINAYO, M.C.S. (Org.). Pesquisa social: teoria, método e criatividade. Petrópolis: Vozes, 1994.

OMS. Organização Mundial de Saúde. Maternidade segura. Assistência ao parto normal: um guia prático. Genebra: OMS, 1996. (Publicação OMS/SRF/MSM/96.24).

RATTNER, D.; TRENCH, B. (Orgs.). Humanizando nascimentos e partos. São Paulo: Senac, 2005

SERRUYA, S.J.; LAGO, T.G.; CECATTI, J.G. O panorama da atenção pré-natal no Brasil e o Programa de Humanização do Pré-natal e Nascimento. Rev. Bras. Saúde Mater. Infant., v.4, n.3, p.269-79, 2004a.

O Programa de Humanização no Pré-natal e Nascimento do Ministério da Saúde no Brasil: resultados iniciais. Cad. Saúde Pública, v.20, n.5, p.1281-9, 2004b.

TEIXEIRA, R.R. O acolhimento num serviço de saúde entendido como uma rede de conversações. In: MATTOS, R.A.; PINHEIRO, R. (Orgs.). Construção da integralidade: cotidiano, saberes e práticas em saúde. Rio de Janeiro: UERJ/ABRASCO, 2001. p. 89-112.

TORNQUIST, C.S. Paradoxos da humanização em uma maternidade no Brasil. Cad. Saúde Pública, v.19, Supl 2, p.419-27, 2003. 
PARADA, C.M.G.L.; TONETE, V.L.P. El cuidado en salud en el ciclo gravídico puerperal bajo la perspectiva de usuarias de servicios públicos. Interface - Comunic., Saúde, Educ., v.12, n.24, p.35-46, jan./mar. 2008.

Este estudio tuvo por objetivo aprehender las representaciones sociales de puérperas sobre el cuidado en salud en el período prenatal, en el parto y en el puerperio, en un contexto regional de servicios públicos de salud del interior de São Paulo. Según el enfoque de investigación cualitativa, los datos fueron cosechados por medio de entrevistas semi-estructuradas realizadas en 2004 y organizados según el método del Discurso del Sujeto Colectivo. El programa de Humanización del Prenatal y Nacimiento (PHPN) se utilizó como referencial teórico para discusión de los resultados. La perspectiva de las puérperas sobre el cuidado en salud en el ciclo gravídico-puerperal evidenció la importancia de las relaciones interpersonales; la esencialidad de la calidad técnica de la atención y la propiedad de la percepción de que es la mujer el sujeto de la atención y, como tal, debe participar efectivamente en ella. Se concluye que las directrices del PHPN deben incorporarse de forma más amplia en las prácticas de salud dirigidas a la mujer y además se recomienda la adopción de indicadores específicos para evaluación de las dimensiones del cuidado evidenciadas en este estudio.

Palabras clave: Cuidado prenatal. Parto. Período pos-parto. Evaluación en salud. Investigación cualitativa. Parto humanizado.

Recebido em 19/04/07. Aprovado em 30/08/07. 